\title{
PARTURIENTE E EQUIPE OBSTÉtRICA: A dIFÍCIL ARTE dA COMUNICAÇÃO
}

Olga Aparecida Fortunato Caron ${ }^{2}$

Isilia Aparecida Silva ${ }^{3}$

Caron OAF, Silva IA. Parturiente e equipe obstétrica: a difícil arte da comunicação. Rev Latino-am Enfermagem 2002 julhoagosto; 10(4):485-92.

O estudo teve como objetivo descrever como ocorre a comunicação entre os profissionais que assistem o parto de baixo risco e a mulher que vivencia o processo de parturição. Os dados foram obtidos por meio da observação participante das situações ocorridas no centro obstétrico de duas instituições e de entrevistas com puérperas. Constatou-se que, entre profissionais e parturientes, prevalece a comunicação não terapêutica, imprimindo à assistência obstétrica um perfil de impessoalidade e exercício de poder do profissional sobre a mulher.

DESCRITORES: comunicação, parto, enfermagem obstétrica

\section{WOMEN IN LABOR AND THE OBSTETRIC TEAM: THE DIFFICULT ART OF COMMUNICATING}

This study aimed at describing how communication is established between professionals assisting low-risk childbirth and women experiencing the parturition process. The results obtained from participant observation and interviews with the puerperae showed that the quality of communication is impaired and there is the prevalence of non-therapeutic communication. Technicism dominates and is permeated by a low level of perception and sensitivity with regard to the actual needs of women in labor. The management of labor and childbirth was most often the simple execution of technical procedures.

DESCRIPTORS: communication, delivery, obstetric nursing

\section{LA PARTURIENTA Y EL EQUIPO OBSTETRICO: EL DIFÍCIL ARTE DE LA COMUNICACIÓN}

En tiempos de atención institucionalizada, se cuestiona la calidad del cuidado ofrecido a la mujer y al niño durante el momento del parto y el nacimiento. Con base en los presupuestos de la teoría de la comunicación, buscamos describir, a través de datos obtenidos por la observación participante y entrevistas, lo que ocurre durante la comunicación entre los profesionales que atienden a la mujer en la condición de parto de bajo riesgo. Se constató que, entre profesionales y parturientas, prevalece la comunicación no terapéutica, otorgando a la atención obstétrica un perfil impersonal y ejercicio de poder del profesional sobre la mujer.

DESCRIPTORES: comunicación, parto, enfermería obstétrica

\footnotetext{
${ }^{1}$ Extraído da dissertação de mestrado apresentada ao Programa de Pós-Graduação da Escola de Enfermagem da Universidade de São Paulo em 1998; ${ }^{2}$ Enfermeira Obstétrica, Mestre em Enfermagem Obstétrica; ${ }^{3}$ Enfermeira Obstétrica, Professor Associado da Escola de Enfermagem da Universidade de São Paulo, e-mail: isasilva@usp.br
} 


\section{INTRODUÇÃO}

A obstetrícia moderna nasceu sob a tutela da cirurgia e transformou o parto e o nascimento em um evento medicalizado, descaracterizando a essência original de fenômeno existencial e psicológico, para mãe e filho, e acontecimento social, para o grupo familiar e sociedade.

Esse modelo prima pela racionalidade, tecnicismo, mercantilismo e pela carência de princípios humanísticos, em que mãe e filho deixam de ser vistos como pessoas e passam de sujeitos para objetos da assistência.

Essa prática assistencial tem provocado crescente angústia nas mulheres, para quem o parto é simbolizado como um evento de riscos e dor física. Atualmente, além do temor inerente ao parto, a mulher sente medo de quem a atenderá, uma vez que suas experiências próprias ou de outras mulheres de seu convívio estão repletas de atendimento impessoal e distante, por parte dos profissionais ${ }^{(1)}$.

Esse panorama indica a necessidade de um modelo assistencial que resgate o processo natural $\mathrm{e}$ humano do parto e do nascimento e freie o abuso das práticas obstétricas inadequadamente intervencionistas. Para tanto, tem-se recomendado a reintrodução da obstetriz ou enfermeira obstétrica nas maternidades públicas e privadas, onde ela é considerada profissional estratégica para a redução dos índices de mortalidade e morbidade perinatal e materna, bem como, para a diminuição dos índices de intervenções cirúrgicas no parto $^{(2)}$.

A atitude da enfermeira, em estabelecer uma comunicação efetiva com sua cliente, constrói uma relação terapêutica, estabelecendo uma condução de trabalho de parto resolutiva e não intervencionista. $O$ diferencial do modelo de assistência adotado pela enfermeira reside em sua capacidade de comunicação e apoio, o que favorece a interação efetiva entre parturiente e profissional ${ }^{(3)}$.

Estudos têm demonstrado que a qualidade das interações entre os profissionais e as pessoas que estão sob seus cuidados está na dependência de uma disponibilidade própria do profissional em estabelecer relações de ajuda e de acolhimento. Acresce-se a isso o fato de os profissionais não se sentirem preparados para interagir com a clientela em conseqüência da falta de conteúdos sobre esse tema em sua formação acadêmica $^{(4)}$.

No entanto, não é possível se conceber o fazer profissional sem se considerar a importância do processo comunicativo nele implícito, uma vez que as formas de comunicação são utilizadas "conscientemente ou não"(5).

Considerando-se as oportunidades de interação entre os profissionais da equipe obstétrica e a parturiente, passamos a indagar como se dá a situação de atendimento à mulher, no trabalho de parto e no parto, do ponto de vista da comunicação.

Dessa maneira, buscamos investigar, no ambiente "natural" das instituições de saúde, a situação atual de atendimento do "parto de baixo risco", com o objetivo de descrever como ocorre a comunicação entre os profissionais que assistem o parto de baixo risco e a mulher que vivencia o processo de parturição.

\section{REFERENCIAL TEÓRICO-METODOLÓGICO}

Comunicar é o processo de transmitir e receber mensagens por meio de signos, sejam eles símbolos ou sinais, verbais ou não-verbais ${ }^{(5)}$. Esse processo media toda a ação da enfermeira e propicia o estabelecimento de um relacionamento efetivo ${ }^{(6)}$. Pela comunicação, podemos compreender a visão de mundo do paciente, identificar o que ele sente, com base no significado que ele atribui aos fatos que the ocorrem. A comunicação, assim estabelecida, gera auto-estima, apoio, conforto, confiança, resultando em segurança e satisfação, facilitando o alcance da excelência do cuidado, do bemestar do paciente, fazendo com que este se sinta respeitado como pessoa nas suas diferentes dimensões: física, psíquica, cultural, espiritual, social e intelectual.

A comunicação não-verbal tem destaque expressivo nos processos interacionais, sendo definida como toda forma de expressão que não inclui as palavras, como a expressão facial, gestos, postura corporal, a relação de distância mantida do outro. Os sinais nãoverbais podem complementar a comunicação verbal, reforçando o que foi expresso verbalmente, substituir a fala, contradizer a mensagem emitida por palavras, ou ainda, demonstrar sentimentos, emoções, em especial pelas expressões faciais ${ }^{(5)}$. 
A comunicação pode ser considerada terapêutica, positiva ou efetiva, quando tem a qualidade curativa ou benéfica, no sentido de ajudar a pessoa a lidar com os eventos da vida e ajustar-se à realidade presente. Nesse sentido, no atendimento à mulher, é possível considerar que a comunicação terapêutica entre o profissional e a parturiente ocorre quando se subsidia uma assistência que proporciona conforto, apoio, confiança e segurança física e emocional, guiando a mulher no curso do trabalho de parto, permitindo e valorizando sua participação nesse processo, de forma a tornar o nascimento de seu filho uma experiência positiva $^{(6)}$.

Por outro lado, a comunicação não terapêutica significa não saber ouvir, usar linguagem inacessível, jargões e termos técnicos, ou frases estereotipadas que podem denotar falta de empatia e desencadear sentimentos depressivos, enfim, bloquear a comunicação. Envolve, também, o julgamento do comportamento do paciente e a emissão de opinião própria sobre si mesmo, tirando-Ihe o direito de tomar decisão em geral, demonstrando a não valorização do outro na relação ${ }^{(6)}$.

Para tornar a comunicação terapêutica, existem estratégias que podem ser implementadas em situação de interação interpessoal com o paciente, facilitando o processo terapêutico e o alcance dos objetivos da assistência de enfermagem ${ }^{(6)}$. Elas são classificadas em 3 grupos: de expressão - que ajudam a descrição da experiência e a expressão de sentimentos, estabelecendo o sentimento de confiança, e referem-se a ouvir reflexivamente, permanecer em silêncio, verbalizar aceitação e interesse, entre outras; de clarificação - que objetivam esclarecer o não entendido pelo paciente, o que pode ser alcançado quando o profissional cria ou aproveita situações de correção ou oferta de informação; de validação - que auxiliam na ocorrência de significação comum do que é expresso, como repetir a mensagem do paciente ou sumarizar o conteúdo da interação.

\section{DESCRIÇÃO DA PESQUISA}

Os componentes materiais e humanos

Trata-se de um estudo descritivo e exploratório de natureza qualitativa.

O estudo foi realizado no centro obstétrico de dois hospitais da rede SUS, do município de São Paulo, sendo um estatal $[A]$ e outro filantrópico $[B]$, com média de 950 e 350 partos/mês, respectivamente.

Participaram do estudo 15 parturientes que não apresentavam história obstétrica e clínica indicativa de parto operatório e que evoluíram para parto normal; duas enfermeiras obstétricas, uma de cada instituição, e dez médicos, sendo seis da instituição $A$ e quatro da $B$, distribuídos em diferentes plantões, sendo que a jornada de trabalho das enfermeiras era de $8 \mathrm{~h}$, diurno, e participavam de todas as equipes de plantão da semana em que se modificava apenas o pessoal médico. A coleta de dados foi realizada por meio da observação participante, focalizando os momentos de interação entre profissionais e as parturientes, nos ambientes de sala de parto e pré-parto. A inserção da pesquisadora no campo propiciou sua participação, em conjunto com os profissionais, nos cuidados de verificação dos batimentos cardíacos do feto (BCF), verificação de dinâmica uterina e conforto à parturiente.

Foram observadas 25 cenas, de forma intermitente, com períodos mínimos de $15 \mathrm{~min}$ e máximo de 30min, e os dados de comunicação verbal e não-verbal foram anotados no local, após cada cena observada. Foram realizadas entrevistas focalizadas com as parturientes observadas, no dia seguinte ao parto. As entrevistas partiram da questão norteadora: conte-me como foi sua experiência do trabalho de parto, e do parto e foram feitas na unidade de puerpério, em local privativo, com gravação consentida pelas mulheres, tendo duração média de 20 min cada uma.

Obteve-se consentimento formal das duas instituições hospitalares, das mulheres e dos profissionais, garantindo-se o direito de voluntariado de participação, o anonimato e sigilo dos dados. As entrevistas foram gravadas e, posteriormente, transcritas na íntegra.

Os dados de observação da comunicação verbal e não-verbal foram analisados conjuntamente, considerando-se que ambas se complementam para a emissão da mensagem e, posteriormente, foram articuladas aos dados de entrevista, que foram analisados, buscando-se os núcleos de sentido nas falas das participantes ${ }^{(7)}$, organizando-se em temas. A saturação dos dados foi o indicativo do encerramento da obtenção das informações. 


\section{RESULTADOS}

Cenas, atores e a comunicação

O conjunto de dados obtidos resultaram em duas categorias as quais optamos por nominar Comunicação Terapêutica e Comunicação Não Terapêutica, considerando que podem melhor expressar os resultados deste estudo em termos da qualificação da assistência prestada à parturiente.

\section{Comunicação terapêutica}

Descrevemos, aqui, situações de interação entre os atores deste estudo, consideradas como Comunicação Terapêutica, por terem demonstrado que os signos de comunicação presentes e a significação destes, para os atores sociais dessa relação, resultaram em entendimento recíproco e propiciaram uma assistência de melhor qualidade à mulher em seu processo parturitivo.

Embora as situações descritas neste estudo não revelem diferença qualitativamente significativa entre as atividades das enfermeiras, e as dos demais profissionais, observou-se que elas foram as que mais se comunicaram terapeuticamente com as parturientes, percebendo os seus sentimentos de medo, dor e a sua ansiedade, o que resultou em assistência efetiva, adequada e menos intervencionista.

Cena 1- Parturiente*, com respiração ofegante, movimentando-se descoordenadamente, agitada. A enfermeira aproximou-se e disse, pausadamente, em tom de voz que denotava calma: Vira bem a barriga para cima que eu quero te examinar. Em seguida realizou o toque obstétrico fitando a parturiente com sorriso, informando-lhe: Ich, tá aqui embaixo, vamos acertar o corpo na cama? Vamos lá que eu te ensino. A parturiente alinhou, rapidamente, o tronco sobre a cama(...), seguiu as orientações dadas. A parturiente continuou fazendo força e olhando para a enfermeira, com um olhar que Ihe solicitava aprovação, a que a enfermeira respondia afirmativamente, mantendo o contato visual com a parturiente, estimulando-a, sinalizando positivamente, com movimentos da cabeça.

Frente à agitação da paciente, a enfermeira aproxima-se e passa a orientá-la no momento oportuno. A resposta da enfermeira à linguagem corporal da parturiente pode ser compreendida por meio do conceito de Cinésia, em que tanto a atitude corporal visível, quanto a atividade fonética audível influenciam o comportamento do outro num sincronismo de comunicação ${ }^{(5)}$. Dizer o que fazer, manter a atenção voltada para a mulher, dar reforço através de meneio positivo da cabeça, encorajou e indicou interesse na parturiente, por parte da profissional.

A importância de a enfermeira promover a participação da mulher no seu trabalho de parto, eliminando as sensações de medo, dor, angústia, pânico, tão comumente referidas pelas parturientes, por meio de uma comunicação efetiva, pode não só resultar em modificação do comportamento da mulher, mas também proporcionar-lhe uma experiência menos amedrontadora, gerando sentimento de confiança e segurança. Isso é confirmado pela mulher no pós-parto, quando a puérpera diz:

(...) incentiva bastante eles tando do nosso lado, os médicos assim ajudando, (...) quando eles tavam comigo eu acertava, fazia de tudo, mas, quando eles saíam, eu ficava sozinha sentindo contração e não fazia força e não adiantava... [Beatriz] ${ }^{* *}$

O cliente sente-se bem tratado e considera 0 cuidador um bom profissional, quando ele demonstra disponibilidade para atendê-lo, o que pode ser compreendido pelas atitudes de permanecer em silêncio, ouvir reflexivamente, verbalizar interesse e aceitação, que se constituem estratégias de comunicação terapêutica ${ }^{(6,8)}$.

Cena 2 - Na sala de parto, encontravam-se a enfermeira e uma parturiente em período expulsivo, posicionada na mesa de partos, em posição ginecológica. Paramentada, a enfermeira procedeu à antissepsia e colocação de campos estéreis, falando à parturiente: ANA, vou passar uma agüinha gelada, não se mexe.

Iniciou a colocação dos campos e voltou a falar com a parturiente: Agora, ANA, não põe mais a mão aqui, pra não dar infecção nem pra você nem pro bebê. Continua fazendo força, isso, não pára.

A parturiente manteve as mãos fixas nas perneiras da mesa e, durante a contração, foi orientada pela enfermeira, que entoava sua voz como se estivesse também segurando a inspiração e fazendo força junto: Enche o peito de ar, segura e força aqui embaixo(...) isso, agora que passou a contração, descansa(...) se prepara para a próxima. Respira devagar pro seu bebê... isso.

A enfermeira demonstrou estar em sintonia com a parturiente. Ao identificar os períodos de contração e os de relaxamento uterino, foi capaz de conduzir e incentivar a participação da mulher no parto, instruindo-a passo a passo e oferendo-lhe encorajamento e estímulo, o que conferiu qualidade à informação. Ao parecer estar "fazendo força junto", a enfermeira utilizou-se de signos da comunicação não-verbal, reforçando e qualificando a fala na interação com a parturiente e permitindo, assim, a compreensão do significado da mensagem enviada.

Por meio do toque instrumental, a enfermeira 
percebe a dinâmica das contrações e aproveita o momento para orientar a parturiente. Ao chamá-la pelo nome, usa a técnica de expressão, que incentiva a verbalização do interesse, numa demonstração de que a parturiente existe como pessoa, com identidade distinta das demais ${ }^{(6)}$. Nesse caso, a enfermeira reforça a importância da colaboração da parturiente, valorizando sua participação no parto.

Essa parceria foi proporcionada pela enfermeira que, ao esclarecer os procedimentos realizados e conduzir a participação da mulher, estabeleceu o processo de interação com a parturiente, capaz de minimizar o temor do parto e dar-lhe segurança. Essa mulher disse em sua entrevista pós-parto:

As enfermeiras tavam lá, não me senti sozinha. É verdade, ajuda muito quando a gente tá com medo e tem alguém assim por perto, a gente se sente mais segura, né? Está sempre do lado... [Ana]

A interação, assim estabelecida, gera confiança e influencia na qualidade da experiência da parturiente, como é possível perceber pela fala de uma delas:

Pra mim, foi importante porque eu tava sozinha, sentindo dor... não tinha ninguém, assim, que nem eu pedi pra você segurar a minha mão. Pra mim... foi importante ter uma pessoa do meu lado que eu pudesse confiar nela..né..? [Leonor]

Percebe-se que as parturientes solicitam alguém ao lado delas, para uma orientação ou mesmo para segurar-Ihes a mão como foi evidenciado em suas falas. Algo que, para elas, traduz-se como apoio, mão amiga, conforto, alívio, carinho, importar-se com elas, segurança e encontrar ânimo.

Cena 3 - A parturiente estava deitada em maca, respirando com ritmo normal, sem gemer. Demonstrava tensão ao segurar com força e apreensivamente o lençol sobre o abdômen. O médico aproximou-se, cumprimentou-a com um sorriso e, após o cumprimento, pegou em suas mãos comentando que estavam frias, ao que ela respondeu que estava muito nervosa e não sabia o que ia acontecer: M:- Fique calma, é porque é seu primeiro...a gente vai orientar você conforme vai acontecendo o parto. Agora, vou escutar o coração do seu bebê.

Disse, deslizando a mão sobre o abdômen da parturiente, que retirou o lençol, permitindo que o médico posicionasse o estetoscópio de Pinard e fizesse a ausculta com o rosto voltado para a gestante, a qual mantinha um sorriso nos lábios. Ao concluir o exame, o médico cobriu o abdômen da mulher, mantendo o sorriso, e disse de forma terna: Tá tudo bem com seu bebê, viu?

Nessa situação, o profissional foi sensível em perceber a ansiedade e apreensão da parturiente, o que foi muito positivo, pois um melhor conhecimento do não- verbal pelo profissional permite que ele perceba, com maior precisão, os sentimentos do paciente e ajuda "a potencializar sua própria comunicação, enquanto elemento transmissor de mensagens"(5).

Percebe-se aqui, um dos sinais não-verbais conceituado como Tacêsica, que são todos os sinais que dão sentido à comunicação tátil( ${ }^{(5)}$. Essa cena nos mostra, ainda, o toque afetivo, ou seja, o contato espontâneo realizado pelo profissional que procedeu ao toque instrumental que, segundo a autora, é o contato físico necessário para realizar um procedimento específico, como aqui, o de auscultar o batimento cardiofetal. Ainda, em concordância com os dizeres da autora, o toque afetivo ou expressivo, descrito nessa cena, denota empatia, apoio, proximidade e carinho pela parturiente. Além de explicar o que iria realizar, preparou a mulher para o procedimento e, ao concluir, deu informação do resultado do exame para a mulher.

De todas as situações observadas neste estudo, a empatia foi o elemento de comunicação que ocorreu com menor freqüência, pois o que mais se encontrou neste estudo foram os repetidos modelos normativos de assistência, que parecem refletir a implementação de rotinas, tanto no cuidado prestado pelo médico, como naquele executado pela enfermeira obstétrica, o que passamos a relatar.

\section{Comunicação não-terapêutica}

No conjunto das interações estabelecidas entre os profissionais da equipe de saúde e as parturientes, no pré-parto e no centro obstétrico, prevaleceu a expressão da comunicação não-terapêutica. Os diversos signos da comunicação, emitidos pelos profissionais, no curso da assistência, resultaram em muitas situações, em elementos de bloqueio da comunicação entre esses atores e, conseqüentemente, comprometeram as relações interpessoais e a qualidade da assistência à parturiente.

A comunicação instituída não só entre os profissionais e sua clientela, mas também entre os membros da equipe, evidencia, mesmo que subliminarmente, o exercício das relações de poder.

É possível observar, nas descrições das situações vivenciadas pelas parturientes deste estudo, que a mulher que recebe assistência busca estabelecer contato. No entanto, sua busca de interação é frustrada 
quando recebe respostas de forma incompleta, de forma incompleta, autoritária, plena de dupla mensagem, impessoal e distante, sem satisfazerem as suas necessidades.

Cena 1 - Deitada em maca, sendo transferida para a sala de partos, movimentando, intensamente, as pernas e braços, de forma descordenada, a parturiente manifestava, com gemidos e expressão facial contraída, a dor que sentia nos períodos de contração - $A$ enfermeira dirigiu-se rispidamente à mulher, em tom autoritário: E: Mãe, pra cair daqui (referindo-se à maca) é um pulo, a senhora tem que ajudar. Agora, o seu nenen vai nascer, e você precisa da gente para ajudar, e, se a gente tiver que brigar com você, não vai dar certo.

A comunicação serve para as pessoas compartilharem idéias, sentimentos, mas também pode ser recurso de opressão psicológica e moral ${ }^{(9)}$.

Em uma situação como essa, a exemplo de outras observadas no campo deste estudo, percebe-se a relação de poder exercida pelo profissional, quando se dirige à mulher de maneira ameaçadora, cerceando-lhe a liberdade de expressão, limitando-se a dar ordens à parturiente, sem dar a ela o espaço de manifestar seus sentimentos.

(...) eu chamava alguém pra perguntar se já não tava na hora, e o médico disse que não tinha necessidade de ficar gritando... que, quando chegasse a hora, ele ia saber muito bem... Virou as costas e foi embora (...) Ele ouviu a pergunta e saiu sem responder... [Amélia]

Eu acho que a enfermeira podia fazer o exame pra dizer se já estava na hora ou não. (...) pelo menos com quantos dedos, o que precisa fazer, como faz a força, como que tá... tudo isso. Ninguém falou nada! [Joana]

A falta de informações e instruções adequadas e necessárias, no decorrer do trabalho de parto e do parto, é percebida pelas pacientes como descaso, provocando nelas o sentimento de indignação, pois sentem-se abandonadas e desrespeitadas. Fica evidente, na cena e falas acima, que a equipe não demonstra a preocupação de informar à parturiente o estágio do parto, nem tampouco de identificar as causas de ansiedade, tensão e medo dessas mulheres.

As parturientes que não mantêm autocontrole sobre suas ações, provocam, nos profissionais, julgamentos e emissões de desaprovação. É preciso lembrar que não são conhecidos os efeitos que tem a repressão de comportamentos tidos como indesejáveis, como gritar, chorar, agitar-se, sobre a saúde mental das mulheres, visto que essas manifestações podem ser meios de alívio de tensão para elas, que, por certo, não encontram outra maneira de atenuar seus temores ${ }^{(10)}$. Cena 2 - M: - Não, não, não solta o ar, segura o ferro e faz força de cocô, pode fazer cocô, força aqui em baixo, força comprida, isso, não pára. A médica olhou para os demais residentes, terminou o toque e sem dirigir-se à mulher falou para os colegas: Já pode levar, vai nascer já, só mais uma forcinha e nasce. Todos os residentes se retiraram para o Centro Obstétrico, à exceção do primeiro deles, que pediu a maca, e com a mão esquerda no joelho da parturiente, e disse: Não faz força não, segura aí. Agora não faz força, repetindo a ordem enfaticamente.

As mensagens, nesse caso, foram emitidas intencionalmente, apenas entre os profissionais, não havendo atenção voltada para a parturiente, exceto no procedimento técnico em que ela figurou como objeto de trabalho.

O corpo amedrontado e envergonhado é mais facilmente disciplinável. Todo saber tem capacidades disciplinadora e normatizadora; saúde é um conhecimento construído na relação entre saber $x$ poder. O poder não é artigo de posse, constitui um conjunto de práticas de poder ${ }^{(11)}$. A criação de normas e modelos de condutas e produção do saber são funções intimamente relacionadas ao próprio poder e utilizadas por ele: poder gera saber que, por sua vez, gera mais poder.

Uma outra cena exemplifica a qualidade das interações estabelecidas entre os atores sociais deste estudo:

Cena 3 - Profissional auscultando os batimentos cardiofetais com o Pinard, mantém-se de costas para a parturiente, com olhos fixos no relógio que segura em sua mão direita. Ao terminar o exame, marcou um X no abdômen da parturiente, com uma caneta, indicando onde foi identificado o "foco" de batimentos, sem justificar tal ato ou solicitar a sua autorização para tal. Cobriu o abdômen da mulher, afastou-se e fez uma anotação no prontuário dela. Não Ihe dirigiu o olhar ou uma palavra antes, durante ou após o exame. Dirigiu-se as outras parturientes da enfermaria, procedendo da mesma forma com as demais.

Durante o período no campo de pesquisa, algumas atitudes dos profissionais que chamaram mais a atenção foram, como as descritas aqui, no que diz respeito à invasão do espaço "pessoal e territorial" da parturiente. Estamos nos referindo ao conceito Proxêmica ${ }^{(5)}$, que indica o uso do espaço feito pelos sujeitos, como a distância que se coloca entre dois indivíduos durante uma interação. O espaço pessoal é aquele que consiste no raio de distância ou de proximidade que o indivíduo permite que o outro 
"adentre", colocado ao seu redor como uma bolha invisível ou imaginária.

Ao aproximar-se, descobrir a parturiente e tocála, mesmo que instrumentalmente, sem pedir permissão ou dizer palavra, o profissional invade esse espaço, bloqueia a comunicação e desrespeita o território legítimo daquela mulher.

Assim, quando tocamos alguém, invadimos seu espaço pessoal. Por isso, é importante ficar atento aos sinais não-verbais que essa pessoa manifesta, demonstrando consentimento ou não do paciente em relação a essa invasão, como sua expressão facial, e sua rigidez muscular ${ }^{(5)}$.

Por outro lado, a relação de poder é evidenciada sempre que os profissionais se mantêm de pé, ao lado da gestante, que, deitada, permanece em uma posição passiva, estando física e emocionalmente à mercê dos procedimentos da equipe.

A mulher é submetida não apenas à relação profissional-paciente, mas também ao papel de mulher que the é imposto pela sociedade. Devido à sua conhecida e antiga condição de submissão dentro dos diversos aparelhos ideológicos (família, escola, etc.), a mulher tende a assumir uma atitude passiva na relação com o médico. Especialmente aquela pertencente a classe social menos privilegiada, sente, ainda mais, o distanciamento entre ela e o médico, um representante de outra classe, e, em virtude desse distanciamento, coloca-se numa posição, não só e puramente de passividade, mas de grande temor ${ }^{(12)}$. De forma geral, é possível perceber que a totalidade das interações estabelecidas pelos profissionais, nesse processo de trabalho, está longe de ser uma relação humanizada, o que é possível ser percebido através da descrição das cenas observadas no estudo.

Assim, este estudo indica-nos que a relação equipe $x$ parturiente é unilateral e de domínio dos profissionais sobre sua cliente, prevalecendo, também, a presença de dupla mensagem, pois na maioria das situações, a comunicação verbal emitida pelo profissional não é confirmada por sua expressão não-verbal.

Os signos de comunicação verbal e não-verbal, emitidos pela parturiente, não são acolhidos pelos profissionais. Os apelos das mulheres, sonorizados em forma de choro, gemidos e gritos, são ouvidos pelos seus cuidadores, que a eles atribuem um significado padrão de mau comportamento e incapacidade de compreensão e participação da mulher no seu processo de parturição.

\section{À GUISA DE CONCLUSÃO E CONSIDERAÇÕES}

O estudo revelou-nos que a parturiente manifesta e busca estabelecer interação com todos os membros da equipe obstétrica, procurando apoio e segurança. Nas cenas observadas, a comunicação ocorrida entre esses atores, profissionais e parturiente, foi predominantemente NÃO-TERAPÊUTICA, e, nas raras situações em que as técnicas de comunicação terapêutica foram empregadas, elas foram executadas, em sua maioria, pela enfermeira.

As situações aqui descritas, levam-nos a crer que o modelo assistencial ao parto e nascimento que vigora na prática, é reducionista, enfoca esses fenômenos na perspectiva da fisiologia e, raramente, abre espaço para a participação da mulher. O novo modelo, que propõe a humanização do parto e do nascimento, terá que romper com atitudes consolidadas de atores, impregnadas de saberes e fazeres bastante diferentes daquilo que, atualmente, está sendo preconizado.

O profissional, dentro do modelo a ser superado, domina e apossa-se do corpo da mulher, guiando-se por uma permissão implícita para a execução do toque instrumental, sem dar atenção aos sentimentos provocados na parturiente.

A partir dessa visão, a atitude materna esperada pelos profissionais, deve corresponder às suas expectativas, uma vez que eles julgam as parturientes de forma generalizada, exigindo que se "comportem" dentro de um padrão modelado por eles. Dessa forma, a mulher é subjugada à autoridade dos profissionais, não encontrando, na maioria das vezes, o acolhimento pelo qual anseia, e que poderia ser demonstrado por uma simples frase: "eu estou aqui com você".

A assistência ao parto e nascimento, descrita neste estudo, é construída por repetidos modelos normativos de assistência, refletidos tanto no cuidado prestado pelo médico, como naquele executado pela enfermeira obstétrica, mesmo que ela seja capaz de desenvolver, mais freqüentemente, interações efetivas.

Poucas foram as situações em que se pôde considerar que houve uma comunicação efetiva entre os profissionais e as mulheres observadas. Na maioria das vezes as mensagens não tinham significado para as parturientes. 
Parece ser de senso comum, entre os profissionais, que as parturientes de classe socioeconômica menos privilegiada são tidas como "naturalmente" ignorantes e agressivas. Essa estigmatização faz com que os profissionais atuem de forma autoritária, tentando "manter o domínio da situação "que ofusca a sua percepção das necessidades reais da mulher.

Carece à equipe de saúde despertar para outras formas de "controle da situação", como a de manter a parturiente confiante, segura, participante do seu processo de parturição, que poderia ser conseguido por meio de processos interacionais efetivos.

O predomínio do tecnicismo, a pouca percepção e sensibilidade dos profissionais podem ser atribuídos ao fato de que essa assistência é, muitas vezes, pensada e idealizada unidirecionalmente por nós, profissionais, que determinamos o que é melhor para o outro, não sendo, se considerando a pessoa a quem se assiste como quem pensa, sente e, muitas vezes, tem plena condição de participar do processo que está vivenciando.

Romper com esse modelo significa que o profissional deve colocar-se inteiramente à disposição do outro, não só fisicamente, quanto emocional e intelectualmente.

Se o parto institucionalizado tem o objetivo de minimizar os riscos do processo de parturição, para mãe e filho, os dados obtidos neste estudo retratam outros riscos para a mulher, causados pela atitude dos profissionais, como o de sentir-se desamparada nos momentos em que solicita ajuda.

\section{REFERÊNCIAS BIBLIOGRÁFICAS}

1. Silva IA Amamentar: uma questão de assumir riscos ou garantir benefícios. São Paulo (SP): Robe; 1997.

2. Grávida pede renascimento das parteiras. Folha de São Paulo 1997 março 9: cad. 3, p. 1-3.

3. Butler J. Supportive nurse-midwife care is associated with a reduced incidence of cesarean section. Am J Obstet Gynecol 1993 maio; 168(5):1407-13.

4. Silva IA Construindo perspectivas para a assistência em amamentação: um processo interacional.[tese]. São Paulo (SP): Escola de Enfermagem/USP;1999.

5. Silva MJP. Comunicação tem remédio - a comunicação nas relações interpessoais em saúde. São Paulo (SP): Gente;1996. 6. Stefanelli MC. Comunicação com paciente: teoria e ensino. $2^{a}$ ed. São Paulo (SP): Robe; 1993.
Diante desses resultados, acreditamos que a atitude de consideração dos sentimentos da parturiente por parte dos profissionais e sua disponibilidade em interagir com a mulher seriam um mínimo de atributos desejáveis daqueles que, nos bancos escolares, escolheram assumir o compromisso de cuidar e preservar a vida do próximo.

Como já mencionado, a década de 90 foi marcada pelo esforço de a enfermeira obstetra resgatar seu espaço no atendimento à parturiente. A atuação dessa profissional tem sido considerada uma estratégia importante para redução nos índices de cesárea e no restabelecimento da humanização do parto e nascimento. Isso se deve à característica humanística de sua formação e à maneira como ela desenvolve a assistência, com maior facilidade de estabelecer interações efetivas com sua clientela ${ }^{(4)}$.

Acreditamos que esse movimento deflagrado pelos profissionais, em especial pelas enfermeiras obstetras, pelos órgãos governamentais e nãogovernamentais, é de suma importância para a construção de um novo modelo de assistência ao parto e ao nascimento. Mas é preciso que os profissionais estejam atentos para que seja, também, assegurado que as enfermeiras sejam capazes de desenvolver habilidade interpessoal para estabelecerem interações efetivas com as parturientes, e, então, fazerem a diferença na qualidade da assistência prestada e não apenas na estatística dos tipos de parto e nos índices numéricos de morbimortalidade materna e infantil.

7. Bogdan RC, Biklen SK. Qualitative research for education: na introduction to theory and methods. Boston (USA): Allyn \& Bacon; 1982.

8. Bites A Junior. Cuidando e descuidando: o significado do cuidado para o paciente. [dissertação]. São Paulo (SP): Escola de Enfermagem/USP; 1999.

9. Bordenave JED. Além dos meios e mensagens: introdução à comunicação como processo, tecnologia, sistema e ciência. $3^{\text {a }}$ ed. Petrópolis (RJ): Vozes; 1998.

10. Bachion MM. Análise do padrão de comunicação oral entre equipe de enfermagem e parturiente. [dissertação]. Ribeirão Preto (SP): Escola de Enfermagem Ribeirão Preto/USP; 1991. 11. Foucault M. Vigiar e punir: nascimento da prisão. Petrópolis (RJ): Vozes; 1997.

12. Pamplona V. Mulher, parto e psicodrama. São Paulo (SP): Ágora; 1990. 